Artikel Riset

DOI : $10.33751 /$ jf.v9i2.1608
Fitofarmaka Jurnal Ilmiah Farmasi

Vol.9, No.2, Desember $2019: 86-95$

p-ISSN : 2087-9164 e-ISSN : 2622-755X

\title{
SEDIAAN TABLET KOMBINASI EKSTRAK DAUN SALAM (Eugenia polyantha) DAN HERBA SELEDRI (Apium graveolens) DENGAN VARIASI JENIS PENGIKAT
}

\author{
Erni Rustiani*, Mira Miranti, Alciee Santika Susanti \\ Program Studi Farmasi FMIPA Universitas Pakuan Bogor, PO Box 452 Bogor 16143 \\ West Java, Indonesia \\ *E-mail: e_rustiani@yahoo.com
}

Diterima :16 Juni 2019

Direvisi : 19 Agustus 2019

Disetujui : 3 September 2019

\begin{abstract}
ABSTRAK
Daun salam (Eugenia polyantha) dan herba seledri (Apium graveolens) memiliki kandungan senyawa flavonoid yang diduga mempunyai efek menurunkan kadar gula di dalam darah. Tujuan penelitian ini adalah menentukan formula tablet ekstrak daun salam dan herba seledri dengan pengikat tertentu yang memiliki mutu terbaik. Ditentukan juga kadar flavonoid yang terkandung dalam ekstrak daun salam, ekstrak herba seledri, dan sediaan tablet. Uji stabilita dilakukan terhadap tablet yang disimpan pada suhu kamar $25-30^{\circ} \mathrm{C}$. Tablet dibuat tiga formula dengan metode granulasi basah menggunakan pengikat yang berbeda yaitu PVP K-30, Na-CMC, dan gelatin dengan konsentrasi masing-masing 4\%. Hasil penelitian menunjukkan tablet yang dihasilkan berwarna krem, berbau khas aromatik, dan memiliki rasa pahit di lidah. Hasil evaluasi mutu tablet untuk seluruh formula memenuhi persyaratan Farmakope Indonesia. Hasil pengujian menunjukkan kadar flavonoid ekstrak kering daun salam sebesar 2,619\%, ekstrak kering herba seledri $2,675 \%$, dan sediaan tablet formula $1(3,432 \%)$, formula 2 $(3,948 \%)$ dan formula $3(4,006 \%)$. Berdasarkan hasil uji stabilita, formula dengan pengikat PVP K-30 merupakan formula terbaik.
\end{abstract}

Kata kunci : Daun salam, Herba seledri, PVP K-30, Na-CMC

\section{TABLET PREPARATION COMBINATION OF BAY LEAF AND HERBS CELERY EXTRACTS WITH VARIATION OF BINDER}

\begin{abstract}
Bay leaf (Eugenia polyantha) and celery (Apium graveolens) herbs contain flavonoid compounds that are thought to have the effect of lowering blood sugar levels. The purpose of this research was to formulated the tablet from bay leaf and celery herb extract with specific binder. The flavonoids levels of extract bay leaf and celery herb extract was also determinated. The stability of tablets stored at room temperature was tested. Tablets were formulated using wet granulation method with three different binder that is PVP K-30, Na-CMC, and gelatin each at a concentration of $4 \%$. The resulting tablet is yellowish cream with aromatic smell and bitter taste. The evaluation of tablets quality for all formulas meet the requirements of Indonesian Pharmacopoeia standard. The flavonoid content of dried leaf extract of Eugenia polyantha was $2.619 \%$, Apium graveolens herb extract was $2.675 \%$, the tablet formula 1 was $3.432 \%$, formula 2
\end{abstract}


was $3.948 \%$ and formula 3 was $4.006 \%$. The stability test shows that the tablet with PVP K-30 binder is the best formula.

Keywords: Eugenia polyantha, Apium graveolens, PVP K-30, Na-CMC

\section{PENDAHULUAN}

Senyawa-senyawa aktif yang terdapat pada daun salam diantaranya alaha yaitu eugenol, tanin dan flavonoid. Senyawa aktif ini digunakan untuk menurunkan kadar gula darah atau sebagai antidiabetes. Daun salam mengandung beberapa vitamin seperti vitamin $C$, vitamin $A$, thiamin, riboflavin, niacin, vitamin $\mathrm{B}_{6}$, vitamin $\mathrm{B}_{12}$ dan folat (Taufiqurrohman, 2015). Dosis 1,36 $\mathrm{mg} / \mathrm{kg}$ BB pada ekstrak air daun salam mempunyai efek menurunkan kadar gula darah pada tikus (Musyrifah et al., 2012). Kandungan senyawa aktif herba seledri yaitu minyak atsiri, flavonoid, saponin, tanin, apigenin, kolin, lipase, dan asparagin. Dosis $50 \mathrm{mg} / \mathrm{kg}$ BB pada ekstrak herba seledri efektif dalam menurunkan kadar gula darah pada tikus putih jantan (Meutia, 2013).

Flavonoid merupakan salah satu senyawa yang terdapat dalam daun salam dan herba seledri yang berperan dalam efek farmakologis. Mekanisme kerja senyawa flavonoid dengan cara menstimulasi sekresi insulin dan menghambat absorbsi glukosa sehingga laju glukosa darah tidak terlalu tinggi (Vidyasagar, 2012).

Sediaan tablet dipilih selain kemudahan pada saat penggunaannya agar tujuan pemberiannya tercapai dengan baik. Tablet memiliki beberapa keuntungan yaitu praktis atau mudah dibawa dan digunakan serta stabil di dalam penyimpanannya (Rori et al., 2016). Kombinasi antara daun salam dan herba seledri di dalam sediaan tablet ini diharapkan dapat memberikan efek farmakologis yang lebih optimal di dalam penurunan kadar gula darah.
Bahan pengikat memberikan daya merekat sehingga tablet tidak pecah atau retak (Anief, 2006). Pembuatan tablet dengan metode granulasi basah pada penggunaan pengikat PVP K-30 disarankan untuk menggunakan pelarut akuadest untuk membantu proses granulasi agar mudah dibasahi (Rahmahuda., 2016). Na-CMC merupakan pengikat yang lazim digunakan dalam pembuatan tablet serta memiliki daya ikat yang lebih kuat (Susilawati et al., 2015). Gelatin sebagai bahan pengikat yaitu dapat digunakan pada senyawa yang sulit diikat, akan tetapi cenderung menghasilkan tablet yang keras sehingga waktu disintregannya membutuhkan waktu yang lama selain itu rentan terhadap mikroba (Lachman et al., 1994). Pembuatan tablet kombinasi ekstrak daun salam dan herba seledri menggunakan pengikat PVP $4 \%$, Na-CMC 4\%, dan Gelatin $4 \%$. Diharapkan diperoleh formula terbaik yang sesuai dengan mutu tablet yang memenuhi syarat formulasi.

\section{METODE PENELITIAN Alat dan Bahan}

Alat-alat yang digunakan dalam penelitian ini antara lain alat-alat gelas, alat pencetak tablet (Korsch $\AA$ ), ayakan, botol plastik, desikator, Disintegration Tester (Vanguard Pharmaceutical MachineryInc USA®), Flowbility tester, Hardness Tester (Schleuniger-2E®), jangka sorong, kain batis, krus, Moisture Balance(AND MX 50®), oven, stopwatch Friability Tester (Vanguard Pharmaceutical Machi-neryInc $($ )), tanur (Ney®), Tap Densitymeter(USP 315-2E Bulk Density Tester®), timbangan digital 
(AND G-120®), dan Vacuum $\operatorname{Dryer}\left(\mathrm{Ogawa}{ }^{\circledR}\right)$.

Bahan-bahan yang digunakan dalam penelitian ini adalah daun salam dan herba seledri, Ac-Di-Sol, Avicel PH 102, Na-CMC, Gelatin,Mg Stearat, PVP K-30, dan Talk, akuades, Asam Sulfat 2 $\mathrm{N}$, Etanol 95\%, $\mathrm{HCl} \mathrm{P}$, larutan Gelatin $10 \%, \mathrm{NaCl} 10 \%(1: 1)$, larutan 3\% Besi (III) Klorida, pereaksi Dragendroff, pereaksi Mayer, dan serbuk Mg.

\section{Pembuatan Ekstrak Kering Daun Salam dan Herba Seledri}

Daun salam dan herbal seledri dibuat menjadi simplisia kering. Ekstrak dibuat dengan menggunakan metode infusa. Serbuk simplisia daun salam sebanyak $1 \mathrm{~kg}$ dimasukkan ke dalam panci dengan akuadest $4 \mathrm{~L}$ (Rahmahuda, 2016). Serbuk simplisia herba seledri sebanyak $1 \mathrm{~kg}$ dimasukkan ke dalam panci dengan akuadest $10 \mathrm{~L}$ (Suwarso dan Anggraeni, 2014). Ekstrak cair yang diperoleh dipekatkan dan dikeringkan dengan Vacuum dryersehingga diperoleh ekstrak kering daun salam dan herba seledri. Ekstrak yang dihasilkan di periksa kadar air (Sudarmadji, 1984), kadar abu dan rendemen (DepKes RI, 2000) dan fitokimia ekstrak seperti alkaloida, flavonoid, saponin, tanin (Hanani, 2015).

\section{Formulasi Tablet Kombinasi Ekstrak Daun Salam dan Herba Seledri}

Tablet dibuat dengan bobot 300 mg per tablet. Sediaan dibuat sebanyak 1000 tablet setiap formula (Tabel 1). Ekstrak kering daun salam, ekstrak herba seledri, PVP-K30, Na-CMC, Gelatin, AcDi-Sol, Avicel PH 102, Talk, dan Mg.Stearat ditimbang sesuai dengan jumlah dalam formula. Masing-masing larutan pengikat dibuat menggunakan pelarut akuades. Setelah larutan pengikat dibuat, semua bahan dicampurkan seperti ekstrak kering daun salam, ekstrak kering seledri, Ac-Di-Sol, Avicel PH 102 lalu diaduk homogen. Massa basah diayak dengan pengayak mesh 8, lalu dikeringkan dalam oven dengan suhu $50^{\circ} \mathrm{C}$ sampai terbentuk granul kering. Setelah proses pengeringan, granul diayak kembali dengan pengayak ukuran mesh12. Granul kering ditambahkan Talk dan $\mathrm{Mg}$ Stearat. Setelah bahan sudah tercampur dilakukan evaluasi granul lalu dicetak menjadi tablet dengan mesin kempa tablet.

Tabel 1. Formula Tablet Kombinasi Ekstrak Daun Salam dan Herba Seledri

\begin{tabular}{lccc}
\hline \multirow{2}{*}{ Bahan } & \multicolumn{3}{c}{ Formula (\%) } \\
& F1 & F2 & F3 \\
\hline Ekstrak Kering Daun Salam & 0,11 & 0,11 & 0,11 \\
Ekstrak Kering HerbaSeledri & 4,83 & 4,83 & 4,83 \\
PVP K-30 & 4 & - & - \\
Na-CMC & - & 4 & - \\
Gelatin & - & - & 4 \\
Ac-Di-Sol & 3 & 3 & 3 \\
Mg Stearat & 1 & 1 & 1 \\
Talk & 2 & 2 & 2 \\
Avicel PH 102 ad & 100 & 100 & 100 \\
\hline
\end{tabular}




\section{Penetapan Kadar Flavonoid Ekstrak Kering}

Kadar flavonoid ditetapkan menggunakan metode Chang (2002) Sebanyak $50 \mathrm{mg}$ ekstrak kering daun salam, $50 \mathrm{mg}$ ekstrak kering herba seledri ditimbang masing-masing. Ekstrak masing-masing dilarutkan dengan metanol sampai $50 \mathrm{~mL}$ dan dikocok selama 10 menit sampai ekstrak larut lalu dipipet sebanyak $10 \mathrm{~mL}$ (setiap ekstrak) dan dimasukkan ke dalam labu ukur 50 mL. Larutan ditambahkan $1 \mathrm{~mL} \mathrm{AlCl}_{3}$ $10 \%, 1 \mathrm{~mL} \mathrm{Na}$ Asetat $1 \mathrm{M}$ dan air suling sampai batas. Larutan dikocok homogen lalu dibiarkan selama waktu optimum, lalu serapan diukur pada panjang gelombang maksimal $430 \mathrm{~nm}$. Absorban yang dihasilkan dimasukkan kedalam persamaan regresi dari kurva standar kuersetin, kemudian dihitung kadar flavonoid (Rahmahuda, 2016).

\section{Penentuan Kadar Flavonoid Tablet}

Sebanyak 20 tablet digerus menjadi serbuk tablet yang halus dan ditimbang. Jumlah serbuk tablet yang ditimbang telah disetarakan dengan 50 mg ekstrak kering daun salam dan $50 \mathrm{mg}$ ekstrak seledri. Kadar flavonoid pada tablet dilakukan tahapan yang sama seperti kadar flavonoid pada ekstrak kering daun salam dan ekstrak kering herba seledri.

\section{Uji Stabilitas}

Tablet dimasukkan dalam kemasan botol plastik putih. Pengujian stabilita dilakukan pada suhu kamar (25$30^{\circ} \mathrm{C}$ ) dengan waktu selama 2 bulan dan setiap 2 minggu sekali dilakukan pengamatan organoleptik, keseragaman bobot, keseragaman ukuran, kekerasan, friabilita, dan waktu hancur tablet.

\section{HASIL DAN PEMBAHASAN \\ Karakteristik Serbuk Simplisia dan Ekstrak Kering Daun Salam}

Serbuk simplisia daun salam yang dihasilkan memiliki warna hijau tua, berbau khas aromatik lemah, dan memiliki rasa yang kelat dapat dilihat pada Gambar 1a. Hasil karakterisik serbuk simplisia ini sesuai dengan DepKes RI (1980). Ekstrak kering daun salam memiliki warna hitam kecoklatan, berbau khas aromatik lemah, dan memiliki rasa yang pahit (Gambar 1b).

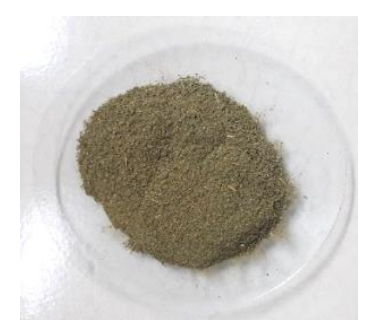

(a)

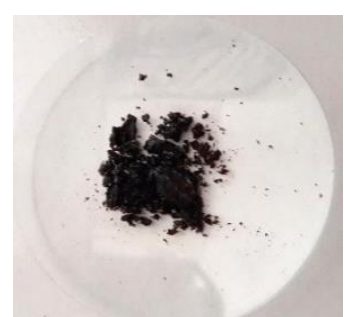

(b)

Gambar 1. Serbuk Daun Salam (a) dan Ekstrak kering daun salam (b)

Kadar air dari ekstrak kering daun salam yang dihasilkan yaitu $1,72 \%$, jika dibandingkan dengan penelitian Rahmahuda (2016) kadar air yang diperoleh ekstrak kering daun salam yaitu 4,46 memenuhi syarat. Kadar abu pada ekstrak kering daun salam yaitu $2,48 \%$. Hasil ini menunjukan bahwa ekstrak 
kering daun salam telah memenuhi syarat. Hasil uji fitokimia yang didapatkan bahwa pada ekstrak kering daun salam menghasilkan senyawa yang mengandung senyawa alkaloid, flavonoid, saponin, dan tanin. Hasil ini sesuai dengan skrining fitokimia yang dilakukan oleh Rahmahuda (2016).

Karakteristik Serbuk Simplisia dan Ekstrak Kering Herba Seledri

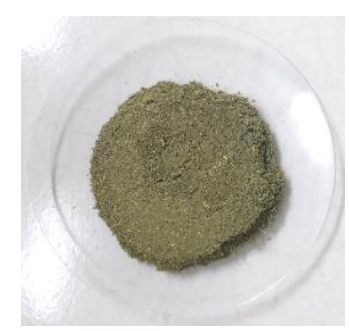

(a)
Serbuk herba seledri memiliki warna hijau muda, berbau khas aromatik tajam, dan memiliki rasa yang pahit. Hasil karakterisik serbuk simplisia ini sesuai dengan DepKes RI (1980) (Gambar 2 a).Ekstrak kering herba seledri memiliki warna hijau kehitaman, berbau khas, dan memiliki rasa yang khas (KeMenKes RI, 2010) (Gambar 2b).

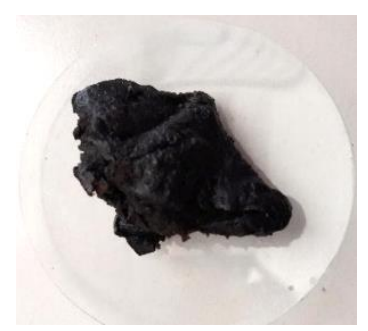

(b)

Gambar 2. Serbuk Herba Seledri (a) dan Ekstrak Herba Seledri (b)

Kadar air ekstrak kering herba seledri yang diperoleh yaitu $2,62 \%$, jika dibandingkan dengan syarat umumnya kadar air ekstrak kering seledri yaitu $10 \%$ (KeMenKes RI, 2010) dan kadar abu ekstrak kering herba seledri yang diperoleh yaitu $4,61 \%$ dan syarat kadar abu ekstrak tidak lebih dari $16,1 \%$ (KeMenKes RI, 2010). Hasil ini menunjukan bahwa serbuk simplisia herba seledri telah memenuhi syarat. Hasil uji fitokimia ekstrak kering herba seledri menghasilkan tiga senyawa yaitu senyawa alkaloid, flavonoid, dan saponin.

\section{Hasil Pembuatan Tablet}

Formula tablet dibuat dengan perbedaan bahan pengikat yaitu PVP K30, Na-CMC, dan Gelatin masing-masing formula dengan metode granulasi basah dan tablet dibuat sebanyak 1000 tablet dengan berat per tablet $300 \mathrm{mg}$.Evaluasi granul dilakukan dengan melakukan uji aliran granul, uji kadar air granul serta uji kompresibilitas (Tabel 2). Perbedaan pengikat yang digunakan tidak memberikan pengaruh yang berbeda terhadap hasil evaluasi granul pada setiap formulanya.

Tabel 2. Hasil Evaluasi Granul

\begin{tabular}{|c|c|c|c|}
\hline \multirow{2}{*}{ Evaluasi Granul } & \multicolumn{3}{|c|}{ Formula } \\
\hline & 1 & 2 & 3 \\
\hline & 6,85 & 6,60 & 7,39 \\
\hline Aliran granul (g/det) & (memenuhi syarat) & (memenuhi syarat) & (memenuhi syarat) \\
\hline Kadar air (\%) & $\begin{array}{c}3,23 \\
\text { (memenuhi syarat) }\end{array}$ & $\begin{array}{c}4,23 \\
\text { (memenuhi syarat) }\end{array}$ & $\begin{array}{c}4,25 \\
\text { (memenuhi syarat) }\end{array}$ \\
\hline Kompresibilitas (\%) & $\begin{array}{c}2,0435 \\
(\neq \text { memenuhi } \\
\text { syarat })\end{array}$ & $\begin{array}{c}2,1293 \\
(\neq \text { memenuhi } \\
\text { syarat })\end{array}$ & $\begin{array}{c}2,5749 \\
(\neq m e m e n u h i \\
\text { syarat })\end{array}$ \\
\hline
\end{tabular}




\section{Hasil Mutu Tablet Organoleptik}

Organoleptik pada masing-masing formula dilakukan pegujianyang berupa bentuknya, bau, warna, sampai dengan rasanya. Tablet yang dihasilkan dengan permukaan atas dan bawah rata, berbau khas aromatik ekstrak, berwarna krem dan memiliki rasa yang pahit pada lidah serta tenggorokan (Gambar 3).

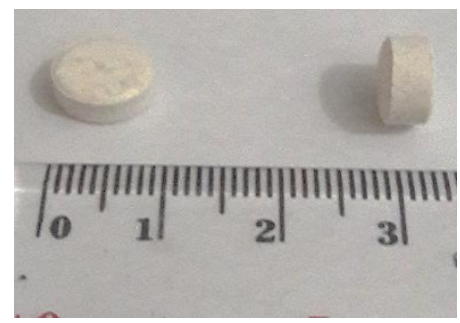

Gambar 3. Tablet Kombinasi Ekstrak Kering Daun Salam dan Seledri

\section{Keseragaman Berat}

Hasil pengujian keseragaman berat dari ketiga formula memenuhi persyaratan keseragaman berat tablet
(DepKes RI, 1979)(Tabel 3).Perbedaan pengikat yang digunakan memberikan hasil yang mutunya sama dan memenuhi syarat Farmakope Indonesia.

Tabel 3. Hasil Uji Keseragaman Berat

\begin{tabular}{lccc}
\hline \multicolumn{1}{c}{ Hasil } & Formula 1 $(\mathbf{m g})$ & Formula 2 $(\mathbf{m g})$ & Formula 3 $(\mathbf{m g})$ \\
\hline Rata-rata & 309,47 & 315,595 & 317,005 \\
Syarat $\pm 5 \%$ & $293,996-324,943$ & $299,816-331,374$ & $301,155-332,855$ \\
Syarat $\pm 10 \%$ & $278,523-340,417$ & $284,036-347,154$ & $285,305-348,705$ \\
\hline
\end{tabular}

\section{Keseragaman Ukuran}

Hasil pengujian keseragaman ukuran dari ketiga formula memenuhi syarat yaitu diameter tablet yang diperoleh tidak lebih dari 3 kali tebal tablet dan tidak kurang dari 1 1/3 kali tebal tablet (DepKes RI, 1979) (Tabel 4). Perbedaan pengikat yang digunakan memberikan hasil sama dan memenuhi persyaratan Farmakope Indonesia.

Tabel 4. Hasil Uji Keseragaman Ukuran

\begin{tabular}{ccccc}
\hline \multirow{2}{*}{ Hasil } & \multicolumn{2}{c}{ Pengukuran rata-rata $(\mathrm{cm})$} & \multicolumn{2}{c}{ Syarat } \\
\cline { 2 - 5 } & Tebal & Diameter & $11 / 3$ & 3 \\
\hline Formula 1 & 0,3915 & 0,959 & 0,522 & 1,1745 \\
Formula 2 & 0,39 & 0,959 & 0,52 & 1,17 \\
Formula 3 & 0,426 & 0,959 & 0,568 & 1,278 \\
\hline
\end{tabular}

\section{Kekerasan}

Uji kekerasan dilakukan pada masing-masing formula untuk mengetahui kekerasan tablet yang dihasilkan. Tablet harus memiliki kekerasan tertentu sehingga kuat tapi mampu melarut di dalam tubuh. Hasil pengujian kekerasan dari ketiga formula memenuhi syarat Parrot (1971) yaitu range kekerasan tablet berkisar antara 4-8 kp (Tabel 5). Perbedaan pengikat yang digunakan memberikan hasil terhadap kekerasan tablet. Formula yang memiliki 
kekerasan paling tinggi adalah formula 1 dengan pengikat PVP K-30.

Tabel 5. Hasil Uji Kekerasan

\begin{tabular}{lcc}
\hline Hasil & Kekerasan rata-rata $(\mathrm{kp})$ & Range $(\mathrm{kp})$ \\
\hline Formula 1 & 8,3035 & $6,93-9,68$ \\
Formula 2 & 6,355 & $4,58-8,97$ \\
Formula 3 & 6,5335 & $5,60-7,84$ \\
\hline
\end{tabular}

\section{Friabilitas}

Hasil pengujian friabilita dari ketiga formula memenuhi syarat karena tidak lebih dari 0,8\%-1\% (Lachman dan Lieberman, 1994) (Tabel 6).Friabilita dilakukan pada masing-masing formula untuk mengetahui kerapuhan dengan cara menghitung banyaknya berat tablet yang hilang pada saat pengujian. Perbedaan pengikat yang digunakan memberikan hasil yang sama dan memenuhi persyaratan.

Tabel 6. Hasil Uji Friabilitas

\begin{tabular}{ll}
\hline \multicolumn{1}{c}{ Hasil } & $\mathrm{f}(\%)$ \\
\hline Formula 1 & 0,384 \\
Formula 2 & 0,252 \\
Formula 3 & 0,489 \\
\hline
\end{tabular}

\section{Waktu Hancur}

Hasil pengujian waktu hancur dilakukan pada masing-masing formula dan diperoleh hasil ketiga formula memenuhi syarat yaitu waktu hancur kurang dari 15 menit (DepKes RI, 1995) (Tabel 7). Waktu hancur ketiga formula memenuhi syarat dipengaruhi oleh superdesintegran yang digunakan yaitu $A c-D i-S o l$ yang memiliki cara kerja penghancuran dengan pengembangan (Devissaguet, 1993). Perbedaan pengikat yang digunakan memberikan hasil tablet yang memenuhi syarat.

Tabel 7. Hasil Uji Waktu Hancur

\begin{tabular}{lc}
\hline Hasil & Waktu hancur rata-rata (menit) \\
\hline Formula 1 & 03 menit 37 detik \\
Formula 2 & 02 menit 42 detik \\
Formula 3 & 01 menit 04 detik \\
\hline
\end{tabular}

\section{Hasil Penelitian Kadar Flavonoid Ekstrak Daun Salam dan Herba Seledri}

Pengujian panjang gelombang maksimum menggunakan larutan standar kuersetin dan pengukuran menggunakan spektrofotometer UV-Vis antara panjang gelombang $405-450 \mathrm{~nm}$. Hasil yang diperoleh adalah serapan maksimum pada panjang gelombang $430 \mathrm{~nm}$ dengan nilai absorbansi 0,814 A.

Hasil waktu inkubasi optimum kuersetin yang didapat yaitu pada menit ke-15 dengan nilai absorbasi 0,801 A. Hubungan antara absorbansidengan konsentrasi memberikan persamaan garis $\mathrm{y}=0,0803 \mathrm{x}-0,0044$ dengan koefisien korelasi $\mathrm{R}^{2}=0,999$. Hasil penetapan kadar flavonoid menunjukkan ekstrak 
kering daun salam memiliki kadar ekstrak kering herba seledri (Tabel 8). flavonoid yang hampir sama dengan

Tabel 8. Kadar Flavonoid Ekstrak

\begin{tabular}{ccc}
\hline Hasil & Kadar Flavonoid (\%) & Rata-rata (\%) \\
\hline Ekstrak Kering Daun Salam & 2,631 & 2,619 \\
& 2,608 & \\
Ekstrak Kering Herba Seledri & 2,646 & 2,675 \\
& 2,704 & \\
\hline
\end{tabular}

Penetapan kadar flavonoid berbeda-beda. Perbedaan kadar dalamtablet dilakukan dengan disebabkan oleh cara granulasi basah melarutkantablet ke dalam pelarut yang dilakukan. Setiap pengikat memiliki metanol Larutan diaduk dengan cara khusus dalam melarutkannya agar magneticstirrer untuk mempercepat memberikan daya merekat yang baik proses pelepasan ekstrak dari sediaan terhadap tablet. Namun hasil kadar tablet dan meningkatkan kelarutannya. flavonoid yang ditentukan berkisar 3-4\% Hasil kadar flavonoid dari setiap formula (Tabel 9).

Tabel 9. Kadar Flavonoid Tablet Kombinasi Ekstrak Daun Salam dan Herba Seledri

\begin{tabular}{rcc}
\hline Hasil & Kadar Flavonoid $(\%)$ & Rata-rata $(\%)$ \\
\hline Formula 1 & 3,323 & 3,432 \\
Formula 2 & 3,540 & \\
& 4,175 & 3,948 \\
Formula 3 & 3,721 & \\
& 4,188 & 4,006 \\
\hline
\end{tabular}

\section{Hasil Pengujian Stabilita Tablet}

Hasil uji stabilita selama 8 minggu terhadap mutu tablet formula 1,2 dan 3 meliputi uji organoleptik, keseragaman berat, keseragaman ukuran, kekerasan, friabilita dan waktu hancur. Berdasarkan hasil uji kekerasan, perbedaan bahan pengikat dalam setiap formula menunjukkan terjadi penurunan nilai kekerasan mulai minggu ke 4 sehingga tidak memenuhi syarat menurut Parrot (1971) yaitu 4-8 kp.

Hasil uji friabilita pada seluruh formula menunjukkan hingga minggu ke 8 formula 1 dan 3 memenuhi syarat, namun formula 2 tidak memenuhi syarat friabilita yaitu tidak lebih dari 0,8\%-1\% (Lachman dan Lieberman, 1994). Tablet yang terbaik adalah formula 1 dengan pengikat PVP K-30 konsentrasi 4\%.

\section{KESIMPULAN}

1. Perbedaan jenis pengikat PVP K-30, Na-CMC dan Gelatin dengan konsentrasi $4 \%$ memberikan hasil tablet dengan mutu yang sama dan memenuhi persyaratan.

2. Formula dengan pengikat PVP K-30 yang disimpan selama 8 minggu pada suhu kamar $\left(25-30^{\circ} \mathrm{C}\right)$ memberikan mutu tablet terbaik.

3. Kadar flavonoid ekstrak kering daun salam 2,619\%, ekstrak kering herba seledri 2,675 \% dan kadar flavonoid tablet 3,432 \% (F1), 3,948 \% (F2), dan $4,006 \%(\mathrm{~F} 3)$. 


\section{REFERENSI}

Anief, M. 2006. Ilmu Meracik Obat Cetakan Kesepuluh. Gadjah Mada University Press. Yogyakarta.

Aulton, M. E. 1988. Pharmaceutics: The Scienceof Dosage from Design. Churchill Livingstone. Edinburg.

Chang, C. C., Yang, M. H., Wen, H. M., \& Chern, J. C. 2002. Estimation of total flavonoid content in propolis by two complementary colorimetric methods. J. Food Drug Ana. 10(3): 178-182.

Departemen Kesehatan R.I. 1979. Farmakope Indonesia, Edisi III. Direktorat Jenderal Pengawasan Obat dan Makanan. Jakarta. 1980. Materia Medika Indonesia, Jilid IV. Direktorat Jenderal Pengawasan Obat dan Makanan. Jakarta.

1995. Farmakope Indonesia. Edisi IV. Direktorat Jenderal Pengawasan Obat Dan Makanan. Jakarta.

2000. Parameter Standar Umum Ekstrak Tumbuhan Obat. Direktorat Pengawasan obat dan Makanan. Jakarta.

2010. Suplemen I Farmakope Herbal Indonesia. Direktorat Pengawasan obat dan Makanan. Jakarta.

- 2008. Suplemen I Farmakope Herbal Indonesia. Direktorat Pengawasan obat dan Makanan. Jakarta.

Devissaguet, J. A. J. 1993. Farmasetika 2 Biofarmasi. Penerjemah Widji Soeratri. Airlangga University Press. Surabaya.

Hanani, E. 2015. Analisis Fitokimia. Penerbit Buku Kedokteran EGC. Jakarta.

Lachman, H. \& Lieberman, J. 1994. Teori dan Praktek Farmasi Industri.
Penerjemah Suyatmi, S., Kawira, J. \& Aisyah, L. UI Press. Jakarta.

Meutia, F. 2013. Pengaruh pemberian ekstrak seledri (Apium graveolens L.) Terhadap Penurunan Kadar Gula Darah Tikus Putih (Rattus norvegicus) jantan yang diinduksi stres listrik. Skripsi. Program Studi Farmasi Fakultas Matematika dan Ilmu Pengetahuan Alam. Universitas Syiah Kuala.

Musyrifah, S. B. Utaminingsih, U. \& Laili, F.N. 2012. Pastiles Daun Salam (Eugenia polyantha W). Universitas Gadjah Mada. Yogyakarta.

Parrot, E. Z. 1971. Pharmaceutical Technology-Fundamental Pharmaceutics. Burgess Publishing Company. USA.

Rahmahuda, N. K. 2016. Formulasi sediaan tablet kombinasi ekstrak daun pepaya dan daun salam dengan variasi konsentrasi pengikat PVP K 30. Skripsi. Program Studi Farmasi Fakultas MIPA. Universitas Pakuan.

Rori, W. M., Paulina, V.Y., Yamlean, Y. \& Sri Sudewi. 2016. Formulasi dan Evaluasi Sediaan Tablet Ekstrak Daun Gedi Hijau (Abelmoschus manihot) dengan metode granulasi basah. Pharmacon Jurnal Ilmiah Farmasi. 5(2): 243-250.

Sudarmadji, S. Haryono, H. \& Suhardi, S. 1984. Prosedur Analisa untuk Bahan Makanan dan Pertanian. Penerbit. Yogyakarta.

Susilawati, I., Kartadarma, E. \& Darma, G.C.E. 2015 Pengaruh bahan pengikat amylum tritici dan CMC$\mathrm{Na}$ terhadap sediaan tablet yang mengandung ekstrak air dan etanol biji jinten hitam (Nigellasativa L.). Prosiding Penelitian SPeSIA. Hal. 
171-178. Universitas Islam Bandung.

Suwarso, E. \& Anggraeni, D.N. 2014. Efek infus daun seledri (Apiumgraviolens L.). Prosiding Seminar Nasional Biologi dan Pembelajarannya. Hal. 302-307. Universitas Negeri Medan.

Taufiqurrohman, T. 2015. Indonesian Bay Laves As Antidiabetic For
Type 2 Diabetes Mellitus. Med. J. Lampung University. 4 (3): 101108.

Vidyasagar, N. 2012. Synthesis of some flavonoid derivatives and study of their antioxidant and in vivo antidiabetic activity. Contemporary Investigation and Observation in Pharmacy. 1: 9-18. 